\title{
Characterization of a cDNA coding for human factor VII
}

(blood coagulation/DNA sequence/vitamin K-dependent proteins)

\author{
Frederick S. Hagen*, Charles L. Gray*, Patrick O’Hara*, Francis J. Grant*, Gena C. SaAri*, \\ Richard G. Woodbury*†, Charles E. Hart*, Maggie Insley*, Walter Kisiel ${ }^{*}$, \\ Kotoku Kurachi§, and EARL W. DaVie§
}

*ZymoGenetics, Inc., 2121 North 35th Street, Seattle, WA 98103; ¥Blood Systems Research Foundation Laboratory, Department of Pathology, University of New Mexico School of Medicine, Albuquerque, NM 87131; and \$Department of Biochemistry, University of Washington, Seattle, WA 98195

\begin{abstract}
Factor VII is a precursor to a serine protease that is present in mammalian plasma. In its activated form, it participates in blood coagulation by activating factor $\mathrm{X}$ and/or factor IX in the presence of tissue factor and calcium. Clones coding for factor VII were obtained from two cDNA libraries prepared from poly(A) RNA from human liver and Hep G2 cells. The amino acid sequence deduced from the CDNAs indicates that factor VII is synthesized with a prepro-leader sequence of 60 or 38 amino acids. The mature protein that circulates in plasma is a single-chain polypeptide composed of 406 amino acids. The amino acid sequence analysis of the protein and the amino acid sequence deduced from the cDNAs indicate that factor VII is converted to factor VII $_{\mathbf{a}}$ by the cleavage of a single internal bond between arginine and isoleucine. This results in the formation of a light chain (152 amino acids) and a heavy chain ( 254 amino acids) that are held together by a disulfide bond. The light chain contains a $\gamma$-carboxyglutamic acid (Gla) domain and two potential epidermal growth factor domains, while the heavy chain contains the serine protease portion of the molecule. Factor VII shows a high degree of amino acid sequence homology with the other vitamin K-dependent plasma proteins.
\end{abstract}

Factor VII is a plasma glycoprotein that participates in the coagulation process leading to the generation of fibrin (1). It is synthesized in the liver where it requires vitamin $\mathbf{K}$ for the formation of approximately $10 \gamma$-carboxyglutamic acid residues that are present in the amino-terminal region of the protein (2). These amino acid residues bind to calcium ions and are involved in the interaction of the protein with phospholipid vesicles. One residue of $\beta$-hydroxyaspartic acid has also been identified in bovine factor VII (3). The biological function of the latter amino acid is not known.

Factor VII is a single-chain glycoprotein $\left(M_{\mathrm{r}} \approx 50,000\right)$ that is secreted into the blood where it circulates in a zymogen form (4-7). Factor VII is converted to factor $\mathrm{VII}_{\mathrm{a}}$ by factor $\mathrm{X}_{\mathrm{a}}(5,8)$, factor $\mathrm{XII}_{\mathrm{a}}(6,9-11)$, factor $\mathrm{IX}_{\mathrm{a}}(11)$, or thrombin (5) by minor proteolysis. This results in the formation of an enzyme composed of two polypeptide chains $\left(M_{\mathrm{r}} \approx 20,000\right.$ and 30,000 ) that are held together by a disulfide bond. The light chain of factor $\mathrm{VII}_{\mathrm{a}}$ contains the $\gamma$-carboxyglutamic acid residues, while the heavy chain contains the catalytic or serine protease portion of the molecule. In the presence of tissue factor and calcium ions, factor $\mathrm{VII}_{\mathrm{a}}$ then converts factor $\mathrm{X}$ to factor $\mathrm{X}_{\mathrm{a}}$ by limited proteolysis, and the latter enzyme in turn converts prothrombin to thrombin in the presence of factor $V_{a}$, calcium ions, and phospholipid. Factor VII $_{\mathrm{a}}$ will also convert factor IX to factor $\mathrm{IX}_{\mathrm{a}}$ in the presence of tissue factor and calcium (12). The relative physiological

The publication costs of this article were defrayed in part by page charge payment. This article must therefore be hereby marked "advertisement" in accordance with 18 U.S.C. $\$ 1734$ solely to indicate this fact. importance of the activation of factor $\mathrm{X}$ versus the activation of factor IX by factor $\mathrm{VII}_{\mathrm{a}}$ is not clear (13).

Deficiencies in factor VII activity are rare, affecting roughly 200-400 individuals in the United States (14). Factor $\mathrm{VII}_{\mathrm{a}}$, however, may be useful in treating patients who have developed inhibitors to factor VIII (15). Accordingly, the preparation of this trace plasma protein by the techniques of recombinant DNA offers a potential source of this coagulation factor that also would be free of viruses, such as those causing hepatitis or acquired immune deficiency syndrome.

This paper describes the isolation and characterization of several clones coding for factor VII employing two different $\lambda g t 11$ expression libraries prepared from poly(A) RNA isolated from human liver and Hep G2 cells. The isolation of a cDNA that encodes the entire factor VII protein sequence makes it possible to express factor VII in a mammalian expression system that synthesizes vitamin K-dependent proteins (16-18).

\section{MATERIALS AND METHODS}

Human $\lambda$ gt11 cDNA Libraries. A $\lambda$ gt11 cDNA library, containing approximately 14 million phage, prepared from poly(A) RNA from human liver was kindly provided by Savio L. C. Woo (19). A second $\lambda$ gt11 cDNA library was prepared from poly(A) RNA from Hep G2 cells by an adaptation of the methods of Gubler and Hoffman (20) and Toole et al. (21). Twelve million recombinant phage were generated from $5 \mu \mathrm{g}$ of poly(A) RNA. Approximately $99.7 \%$ of the phage were recombinants based on $\beta$-galactosidase activity.

Screening of the Agt11 cDNA Libraries. Human factor VII was prepared as described (22), and rabbit antibodies (23) or monoclonal antibodies (24) were prepared and affinity purified by the method of Canfield and Kisiel (23). The purified monoclonal or polyclonal antibodies were labeled with ${ }^{125} \mathrm{I}$ and used to screen filter blots as described by Young and Davis $(25,26)$. The $\lambda g t 11$ libraries were also screened with nick-translated factor VII cDNA (27).

DNA Sequence Analysis. The cDNAs were sequenced by the dideoxy chain termination method (28) using M13 universal primers and factor VII-specific oligonucleotide primers, and by the chemical degradation method of Maxam and Gilbert (29). Oligonucleotides were synthesized on an Applied Biosystems (Foster City, CA) oligonucleotide synthesizer.

Preparation of Human Factor VII for Amino Acid Sequence Analysis. Human factor VII was partially purified through the DEAE-Sepharose step essentially as described by Broze and Majerus (6). Factor VII from the DEAE-Sepharose step was then purified to homogeneity by immunoaffinity chromatog-

\footnotetext{
Abbreviation: Gla, $\gamma$-carboxyglutamic acid.

†Present address: Department of Biochemistry, University of Washington, Seattle, WA 98195.
} 
raphy using a column containing murine monoclonal antibody to human factor VII coupled to activated $\mathrm{CH}$-Sepharose (Pharmacia). The affinity column was equilibrated with 0.05 $\mathrm{M}$ Tris $\cdot \mathrm{HCl}$ buffer, $\mathrm{pH} 7.5$, containing $0.15 \mathrm{M} \mathrm{NaCl}$, and the adsorbed factor VII was eluted from the column with the same Tris-buffered saline containing $3 \mathrm{M}$ NaSCN. Factor $\mathrm{VII}_{\mathrm{a}}$ was prepared by incubating factor VII with human factor $X_{a}(1: 1000$, enzyme:substrate weight ratio) for $30 \mathrm{~min}$ in the presence of $5 \mathrm{mM} \mathrm{CaCl}_{2}$ and dilute human brain phospholipids. Following complete activation, factor $\mathrm{VII}_{\mathrm{a}}$ was separated from factor $\mathrm{X}_{\mathrm{a}}$ and phospholipids by immunoaffinity chromatography under the same conditions used to isolate factor VII.

Protein Sequence Analysis. Human factor $\mathrm{VII}_{\mathrm{a}}(2 \mathrm{mg})$ was reduced and carboxymethylated by the method of Crestfield et al. (30), and the heavy and light chains were separated by HPLC (Varian $\mathrm{C}_{18}$ Micropak column) employing an acetonitrile $/ \mathrm{H}_{2} \mathrm{O}$ gradient containing $0.1 \%$ trifluoroacetic acid. The light chain of factor $\mathrm{VII}_{\mathrm{a}}$ was then digested with chymotrypsin overnight at $37^{\circ} \mathrm{C}$ in $0.1 \mathrm{M}\left(\mathrm{NH}_{4}\right) \mathrm{HCO}_{3}, \mathrm{pH}$ 7.8, with an enzyme-to-substrate ratio of 1 to 100 . The digest was then fractionated by HPLC into about 12 peaks, as described above, and each peak was subjected to Edman degradation using a gas-phase protein sequenator, model 470A (Applied Biosystems).

\section{RESULTS AND DISCUSSION}

A radiolabeled monoclonal antibody to human factor VII was used to screen 6 million phage from a $\lambda$ gt 11 expression library containing cDNA inserts prepared from poly(A) RNA from human liver $(25,26)$. A positive clone ( $\lambda$ HVII2115) was isolated and plaque purified, and its cDNA insert was sequenced by the dideoxy chain termination method (Fig. 1). The cDNA insert was shown to code for factor VII by comparison of the predicted amino acid sequence with that

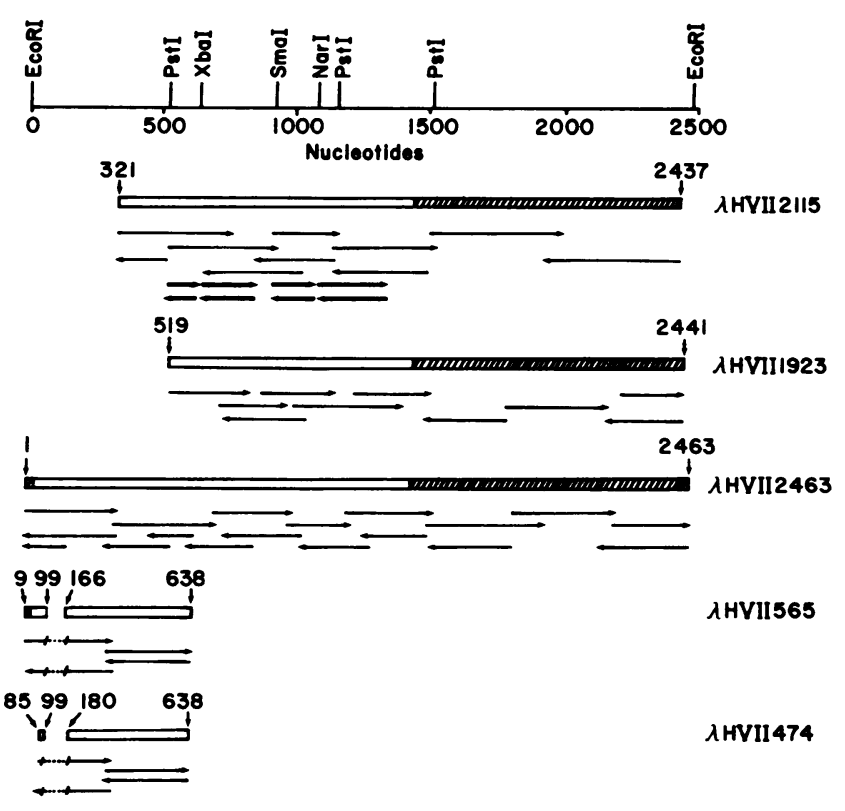

FIg. 1. Partial restriction maps and sequencing strategy for the cDNA inserts in clones $\lambda H V I I 2115, \lambda H V I I 1923, \lambda H V I 12463$, $\lambda H V I I 565$, and $\lambda H V I I 474$. The extent of sequencing is shown by the length of each arrow, and the direction of the arrow indicates the strand that was sequenced. The heavy arrows indicate where Maxam and Gilbert sequencing was performed. The hatched bars indicate the $5 '$ - and 3 '-noncoding regions in each cDNA insert. The nucleotide numbers of the ends and break points of the cDNA inserts are indicated. determined by amino acid sequence analysis of the human protein (22). Also, comparison with the known amino acid sequence of the amino-terminal portions of factor VII (22), factor IX (31), and factor X (32) indicated that this cDNA started with the DNA sequence encoding amino acid 36 of the mature factor VII (nucleotide 321, Fig. 2) and lacked the coding sequence for the amino-terminal region of the protein and a leader sequence. This clone also lacked two nucleotides (at positions 1005 and 1106, Fig. 2) that evidently arose from errors by reverse transcriptase (33). These nucleotides were present in other cDNA clones and in factor VII genomic DNA clones (P.O., unpublished data).

One other factor VII cDNA clone ( $\lambda$ HVII1923) was obtained from the human liver $\lambda$ gt11 library when 14 million phage were screened with a nick-translated fragment of clone $\lambda$ HVII2115. This probe included nucleotides 320-635 (Fig. 2). The cDNA insert in $\lambda$ HVII1923 contained nucleotides 515-2441 (Fig. 2) and did not contain the two nucleotide deletions of clone $\lambda H$ VII 2115 .

To obtain the $5^{\prime}$ end of the DNA coding for factor VII, a second cDNA library was constructed in $\lambda \mathrm{gt} 11$ from poly $(\mathrm{A})$ RNA from Hep G2 cells. One million phage from this library were screened with a nick-translated fragment from clone $\lambda$ HVII2115 (nucleotides 320-625, Fig. 2). Three additional clones were obtained from this library and characterized. The phage $\lambda$ HVII2463 contained the largest factor VII cDNA insert with the sequence of nucleotides 1-2463 (Fig. 2). The other two clones contained sequences from the $5^{\prime}$ end of the cDNA and lacked a stretch of nucleotides coding for part of the factor VII leader sequence present in $\lambda H V I I 2463$. These included nucleotides $100-165$ for the insert in clone $\lambda$ HVII565, and nucleotides 100-179 for the cDNA of clone $\lambda$ HVII474 (Figs. 1 and 2). These two clones were evidently generated by an oligo(dT) priming event at the adenosine-rich region at position 638-649 (Fig. 2) during the first-strand synthesis of the cDNA. The deletion in $\lambda$ HVII474 results in a frame shift for the remainder of the amino acids for factor VII and does not represent an authentic coding sequence for the protein. The absence of nucleotides $100-165$ in clone $\lambda H V I I 565$ indicated that this clone coded for a leader peptide of 38 amino acids rather than a leader peptide of 60 amino acids that was predicted by clone $\lambda$ HVII2463. When compared to the factor VII genomic sequence, these differences in cDNA sequences appeared to result from alternative splicing events (P.O., unpublished data). These analyses, therefore, predict that factor VII mRNA contains a sequence coding for a leader peptide of 60 or 38 amino acids, 406 amino acids of mature factor VII, 1026 nucleotides of 3 '-noncoding sequence, and a poly (A) tail.

The leader sequence predicted by clone $\lambda H$ VII 2463 and clone $\lambda$ HVII565 contained four arginine residues prior to the sequence of Ala-Asn-Ala-Phe-Leu, which is the aminoterminal sequence of human factor VII circulating in plasma. Since the bond between arginine and alanine is an unlikely cleavage site for signal peptidase (34), it is evident that factor VII is synthesized with a prepro-leader sequence analogous to the other vitamin K-dependent coagulation factors. Accordingly, it seems likely that signal peptidase cleaves the newly synthesized polypeptide at a peptide bond upstream from the Arg-Ala sequence. The bond between arginine and alanine would be cleaved by an additional processing protease(s) to yield the mature protein with an aminoterminal alanine (Fig. 3). Two potential initiation methionines are present in the prepro-leader sequence in clone $\lambda \mathrm{HVII}$ 2463. These occur at codon positions -60 and -26 . The methionine at codon -60 , however, is the most likely start site since only this methionine is followed by a hydrophobic region typical of signal peptides. The deletion of 66 nucleotides in clone $\lambda$ HVII 565 removes amino acids -18 to -39 . A messenger with this sequence would code for a prepro-leader 
Met Val Ser Gln Ala Leu Arg Leu Leu Cys $\stackrel{-50}{-60}$ Leu Leu Gly Leu Gln Gly Cys Leu Ala Ala Gly Gly Val

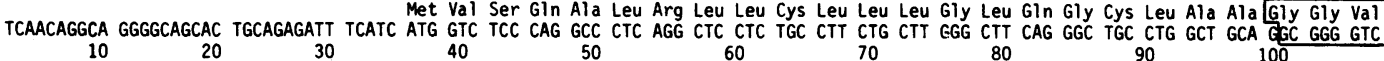

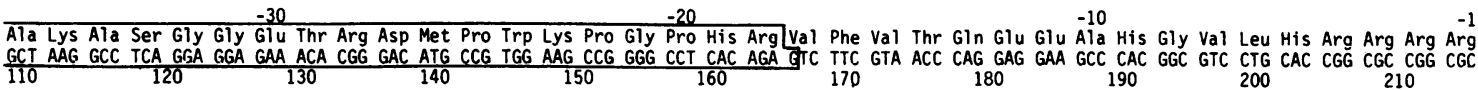

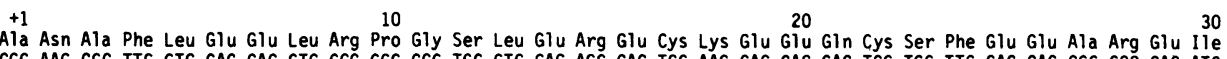
GAG

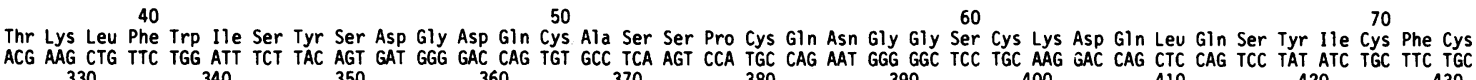
$\begin{array}{lllllllll}330 & 340 & 350 & 360 & 370 & 380 & 390 & 400 & 410\end{array}$ Leu Pro Ala Phe Glu Gly Arg Asn Cys Glu Thr His Lys Asp Asp Gin Leu Ile Cys Val Asn Glu Asn Gly Gly Cys Glu Gin Tyr Cys Ser Asp His Thr Gly Thr
CTC CCT GCC TTC GAG GGC CGG AAC TGT GAG ACG CAC AAG GAT GAC CAG CTG ATC TGT GTG AAC GAG AAC GGC GGC TGT GAG CAG TAC TGC AGT GAC CAC ACG GGC ACC $\begin{array}{rrrrrrrrr}440 & 450 & 460 & 470 & 480 & 490 & 500 & 510 & 520\end{array}$ 110
Lys Arg Ser Cys Arg Cys His Glu Gly Tyr Ser Leu Leu Ala Asp Gly Val Ser Cys Thr Pro Thr Val Glu Tyr Pro Cys Gly Lys Ile Pro Ile Leu Glu Lys Arg
AAG CGC TCC TGT CGG TGC CAC GAG GGG TAC TCT CTG CTG GCA GAC GGG GTG TCC TGC ACA CCC ACA GTT GAA TAT CCA TGT GGA AAA ATA CCT ATT CTA GAA AAA AGA
540
540 Asn Ala Ser Lys Pro 150180

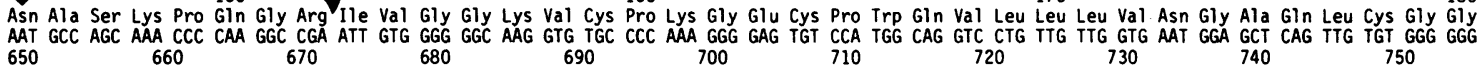
Thr Leu Ile Asn Thr lle Trp Val Val Ser Ala Ala His Cys Phe Asp Lys Ile Lys 200 Asn Trp Arg Asn Leu lle Ala Val Leu Gly Glu His Asp Leu Ser Glu His ACC CTG ATC AAC ACC ATC TGG GTG GTC TCC GCG GCC CAC TGT TTC GAC AAA ATC AAG AAC TGG AGG AAC CTG ATC GCG GTG CTG GGC GAG CAC GAC CTC AGC GAG CAC

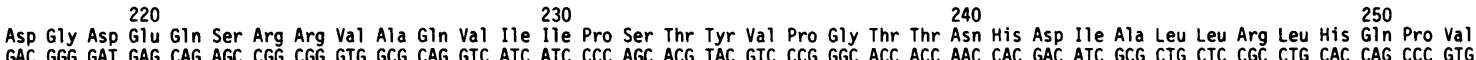
220
Asp Gly Asp Glu Gln Ser Arg Arg Val Ala Gin Val Ile Ile Pro Ser Thr Tyr Val Pro Gly Thr Thr Asn His Asp Ile Ala Leu Leu Arg Leu His Gln Pro Val

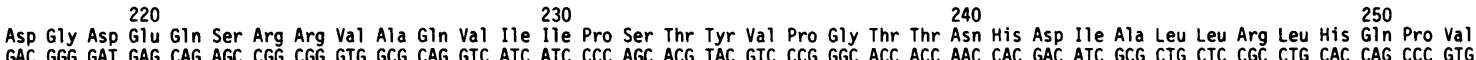
GAC GGG GAT GAG CAG AGC CGG CGG GTG GCG CAG GTC ATC ATC CCC AGC ACG TAC GTC CCG GGC ACC ACC AAC CAC GAC ATC GCG CTG CTC CGC CTG CAC CAG CCC GTG

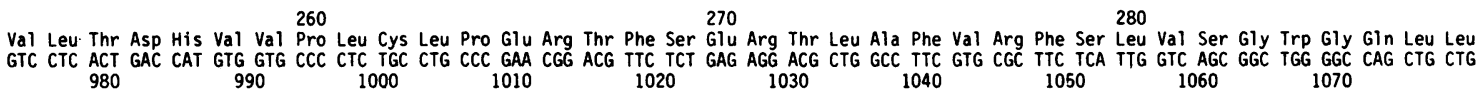
290
Asp Arg Gly Ala Thr Ala Leu Glu Leu Met val Leu Asn Val Pro Arg leu Met Thr Gin Asp Cys Leu Gin Gin Ser Arg Lys val Gly Asp Ser Pro Asn Ile Thr
GAC CGT GGC GCC ACG GCC CTG GAG CTC ATG GTG CTC AAC GTG CCC CGG CTG ATG ACC CAG GAC TGC CTG CAG CAG TCA CGG AAG GTG GGA GAC TCC CCA AAT ATC ACG

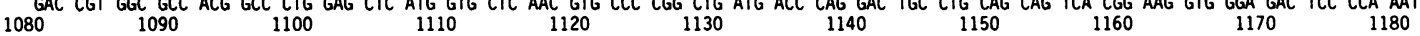

Glu Tyr Met Phe Cys Ala Gly Tyr Ser Asp Gly Ser Lys Asp Ser Cys Lys Gly Asp Ser Gly Gly Pro His Ala Thr His Tyr Arg Gly Thr Trp Tyr Leu Thr Gly \begin{tabular}{l} 
Glu Tyr Met Phe Cys Ala Gly Tyr Ser Asp Gly Ser Lys Asp Ser Cys Lys Gly Asp Ser Gly Gly Pro His Ala Thr His Tyr Arg Gly Thr Trp Tyr Leu Thr Gly \\
GAG TAC ATG TTC TGT GCC GGC TAC TCG GAT GGC AGC AAG GAC TCC TGC AAG GGG GAC AGT GGA GGC CCA CAT GCC ACC CAC TAC CGG GGC ACG TGG TAC CTG ACG GGC \\
1190 \\
\hline
\end{tabular} Ile Val Ser Trp Gly Gln Gly Cys Ala Thr Val Gly His Phe Gly Val Tyr Thr Arg Val Ser Gin Tyr Ile Glu Trp Leu Gln Lys 390 Leu Met Arg Ser Glu Pro Arg ATC GTC AGC TGG GGC CAG GGC TGC GCA ACC GTG GGC CAC TIT GGG GTG TAC ACC AGG GTC TCC CAG TAC ATC GAG TGG CTG CAA AAG CTC ATG CGC TCA GAG CCA CGC

Pro gly Val Leu Leu Arg Ala Pro Phe Pro STOP

Pro gly Val Leu Leu Arg Ala Pro Phe Pro STOP

CCA GGA GTC CTC CTG CGA GCC CCA ITT CCC TAG CCCAGCAGCC CTGGCCTGTG GAGAGAAAGC CAAGGCTGCG TCGAACTGTC CTGGCACCAA ATCCCATATA ITCTTCTGCA GITAATGGGG

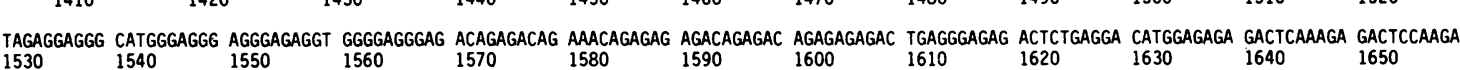
ITCAAAGAGA CTAATAGAGA CACAGAGATG GAATAGAAAA GATGAGAGGC AGAGGCAGAC AGGCGCTGGA CAGAGGGGCA GGGGAGTGCC AAGGTTGTCC TGGAGGCAGA CAGCCCAGCT GAGCCTCCTT

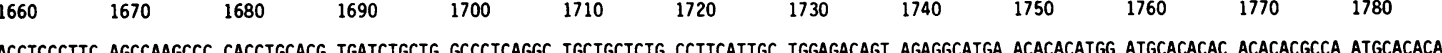

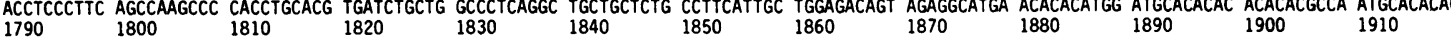
ACAGAGATAT GCACACACAC GGATGCACAC ACAGATGGTC ACACAGAGAT ACGCAAACAC ACGGATGCAC ACGCACATAG AGATATGCAC ACACAGATGC ACACACAGAT ATACACATGG ATGCACGCAC 19201930 G

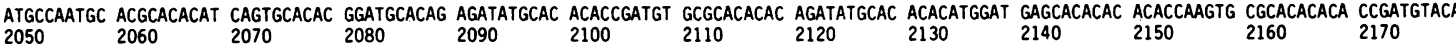
CACACAGATG CACACACAGA TGCACACACA CCGATGCTGA CTCCATGTGT GCTGTCCTCT GAAGGCGGTT GTTTAGCTCT CACTTTTCTG GITCTTATCC ATTATCATCT TCACTTCAGA CAATTCAGAA 22302300 GCATCACCAT GCATGGTGGC GAATGCCCCC AAACTCTCCC CCAAATGTAT TTCTCCCTTC GCTGGGTGCC GGGCTGCACA GACTATTCCC CACCTGCTTC CCAGCTTCAC AATAAACGGC TGCGTCTCCT CCGCACACCT GTGGTGCCTG CCACCCAAAA AAAAAAAAAA AAAAAAA $2440 \quad 2450 \quad 2460 \quad 2470 \quad 2480$

FIG. 2. Nucleotide sequence of the cDNA insert in clone $\lambda$ HVII2463. Residues -60 to -1 represent the prepro-leader sequence for the insert in clone $\lambda H V I I 2463$. The boxed nucleotides and amino acids are those that are absent in clone $\lambda H V I I 565$, resulting in a prepro leader sequence of 38 amino acids. Residues 1 through 406 represent the sequence of the mature factor VII present in plasma. The apparent carbohydrate binding

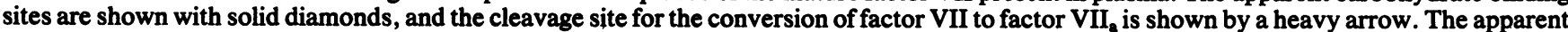
polyadenylylation or processing signal is shown with lines above and below the nucleotides.

sequence with a size and hydrophobicity pattern similar to those of human prothrombin $(35)$, protein $C(36,37)$, and factor IX $(38,39)$.

The amino-terminal region of human factor VII contains 10 glutamic acid residues that are probable sites for carboxylation. These residues are located in positions analogous to those for the $\gamma$-carboxyglutamic acid residues in the other vitamin K-dependent proteins and, therefore, most likely constitute the $\gamma$-carboxyglutamic acid (Gla) domain of factor VII (Fig. 3). The Gla domain in the vitamin $\mathrm{K}$-dependent proteins is involved in calcium binding and, by analogy to the other vitamin K-dependent proteins, the Gla domain in factor VII is probably required for its binding to the phospholipidtissue factor complex during the coagulation process.

The Gla domain in factor VII is followed by two potential growth factor domains (Fig. 3). The function of these do- 


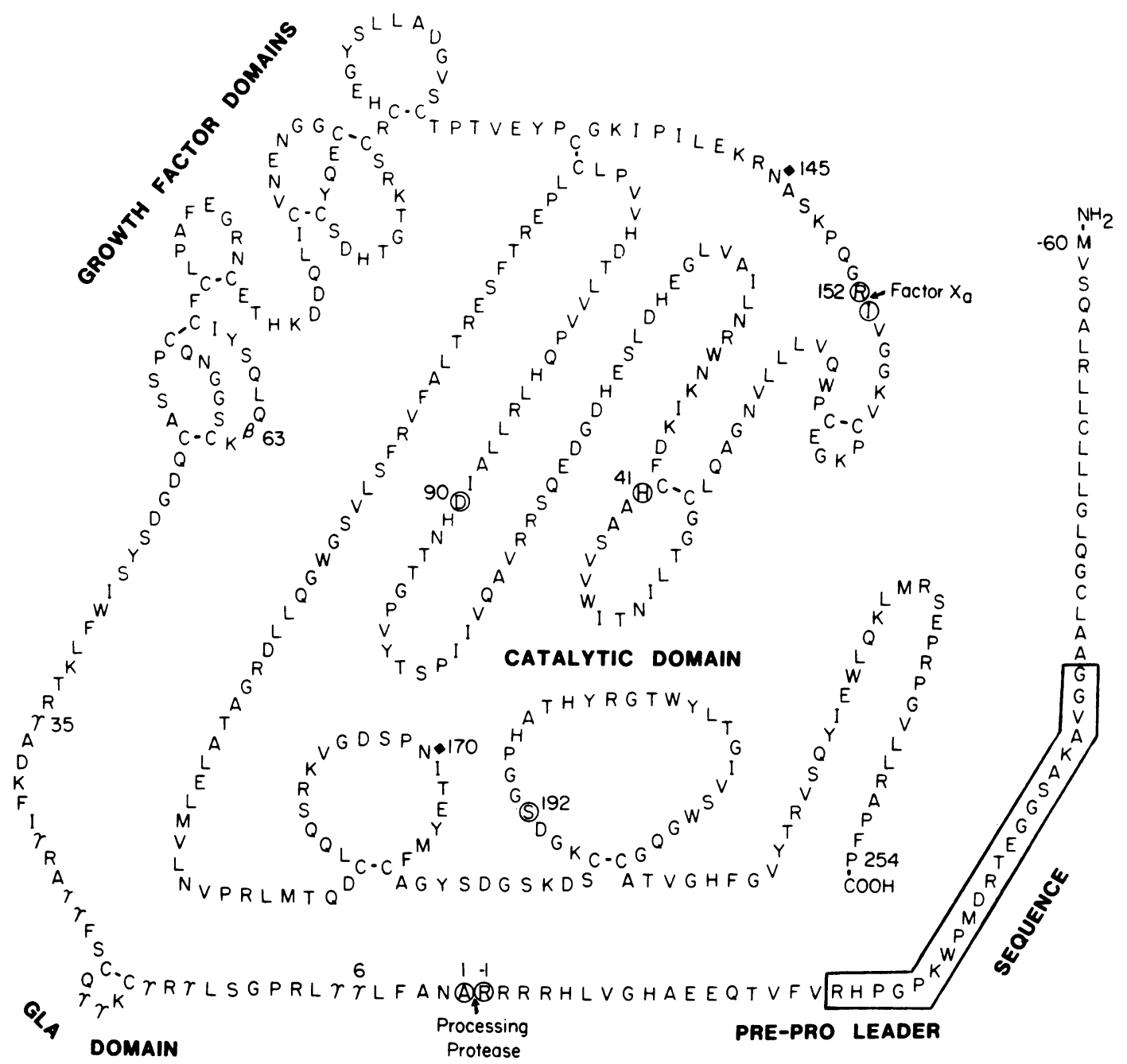

FIG. 3. Amino acid sequence and tentative structure for prepro-factor VII. The prepro-leader sequence of 60 amino acids (numbered -60 to -1$)$ or 38 amino acids is removed during biosynthesis by signal peptidase and a processing protease that cleaves the arginine-alanine $(R-A)$ bond between -1 and 1 . The boxed amino acids are absent in the cDNA insert in $\lambda$ HVII565, resulting in a prepro leader sequence of 38 amino acids. The Gla domain and potential growth factor domains are located within residues 1-152 and constitute the light chain of factor VII ${ }_{\mathrm{a}}$. The site of cleavage in factor VII by factor $\mathrm{X}_{\mathrm{a}}$ is shown by an arrow, and the amino acids where this cleavage occurs are circled. The serine protease or catalytic domain of factor $\mathrm{VII}_{\mathrm{a}}$ contains 254 residues, including the three principal amino acids participating in catalysis. These three amino acids [histidine (H)-41, aspartic acid (D)-90, and serine (S)-192] are also circled. Two potential carbohydrate binding sites are shown by solid diamonds. The tentative disulfide bonds in factor VII have been placed by analogy to those in bovine prothrombin and epidermal growth factor. $\gamma, \gamma$-carboxyglutamic acid; $\beta, \beta$-hydroxyaspartic acid. The first amino acids in the light and heavy chains of factor VII $_{\mathrm{a}}$ start with number 1 and differ from the numbers shown in Fig. 2.

mains is unknown. They were first noted in factor $X(40,41)$ and are also present in factor IX and protein C (36). The first potential growth factor domain contains the sequence of Gly-Ser-Cys-Lys-Asp-Gln-Leu (starting with glycine-59). This sequence is nearly identical to that in bovine factor VII in which the aspartic acid is present as $\beta$-hydroxyaspartic acid (3). Furthermore, $\beta$-hydroxyaspartic acid is present in essentially the same position in factor IX, factor $X$, and protein $C(3,42)$. Thus, it is extremely likely that human factor VII also contains $\beta$-hydroxyaspartic acid at residue 63 in the first potential growth factor domain.

The conversion of factor VII to factor $\mathrm{VII}_{\mathrm{a}}$ is due to the cleavage of the bond between arginine-152 and isoleucine-153 by proteases such as factor $\mathrm{X}_{\mathrm{a}}$, factor $\mathrm{XII}_{\mathrm{a}}$, or thrombin. This results in a new amino-terminal sequence of Ile-Val-Gly-Glyfor the heavy chain of factor VII $_{a}$ (22) (Fig. 3). The heavy chain (254 amino acids) is attached to the light chain (152 amino acids) by a disulfide bond. This bond has been tentatively placed between cysteine- 135 in the light chain and cysteine-110 in the heavy chain by analogy to the other vitamin K-dependent proteins. The heavy chain of factor $\mathrm{VII}_{\mathrm{a}}$ also contains the three principal residues involved in the catalytic activity of this serine protease, including histidine41, aspartic acid-90, and serine-192 (Fig. 3). These residues are analogous to histine-57, aspartic acid-102, and serine-195 in the active site of chymotrypsin (43). Also, aspartic acid-186 in the heavy chain of factor VII $_{a}$ is probably located in the bottom of the substrate binding pocket of the enzyme. An aspartic acid residue in this position is characteristic of the trypsin family of serine proteases that are specific for the hydrolysis of peptide bonds containing a basic amino acid. This sequence in the active site of factor $\mathrm{VII}_{\mathrm{a}}$ is also consistent with the cleavage of a specific bond between arginine and isoleucine in factor $X$ and between arginine and alanine and between arginine and valine in factor IX by this enzyme.

To examine whether an activation peptide is released from the carboxyl terminus of the light chain during the activation reaction, factor $\mathrm{VII}_{\mathrm{a}}$ was reduced and carboxymethylated, and the light and heavy chains were separated by HPLC. The 
light chain was subjected to digestion with chymotrypsin, and the fragments were separated by HPLC and subjected to amino acid sequence analysis. One fragment gave a sequence of Glu-Lys-Arg-Xaa-Ala-Ser-Lys-Pro-Gln-Gly-Arg. This sequence is identical to that predicted by the cDNA starting with glutamic acid-142 and originates from the carboxylterminal end of the light chain of factor $\mathrm{VII}_{\mathrm{a}}$. These data provide strong evidence for the conclusion that the cleavage of a single internal bond between arginine and isoleucine in factor VII leads to the activation of the zymogen. Whether additional cleavages occur in vivo, however, cannot be ruled out.

The amino acid composition of human factor VII circulating in plasma as predicted from the cDNA was determined as follows: Asp $19, \mathrm{Asn}_{13}, \boldsymbol{\beta}-\mathrm{OH} \mathrm{Asp} \mathrm{Ahr}_{12}, \mathrm{Ser}_{29}, \mathrm{Glu}_{17}, \mathrm{Gln}_{20}$, $\mathrm{Gla}_{10}, \mathrm{PrO}_{21}, \mathrm{Gly}_{37}, \mathrm{Ala}_{21}, \mathrm{Val}_{27}, \mathrm{Met}_{4}, \mathrm{Ile}_{17}, \mathrm{Leu}_{38}, \mathrm{Tyr}_{12}$, $\mathrm{Phe}_{13}, \mathrm{Lys}_{17}, \mathrm{His}_{12}, \mathrm{Arg}_{24}, 1 / 2 \mathrm{Cys}_{24}$, and Trp. The molecular weight for the protein free of carbohydrate was calculated as 45,512. This calculation assumes the presence of $10 \mathrm{Gla}$ residues and $1 \beta$-hydroxyaspartic acid residue in factor VII, as discussed. Human factor VII contains two potential amino acid sequences for attachment of carbohydrate chains to asparagine residues. These sequences (Asn-Ala-Ser and Asn-Ile-Thr) occur at asparagine-145 in the light chain and asparagine-170 in the heavy chain (Fig. 3). Addition of two carbohydrate chains would increase the molecular weight for the glycoprotein to about 50,000 . Human factor VII is highly homologous with the other vitamin $\mathrm{K}$-dependent proteins, such as prothrombin ( $25 \%$ identity) (35), factor IX (40\% identity) (38), factor X (40\% identity) (44), and protein C (40\% identity) $(36,37)$. This is consistent with the concept that this family of plasma proteins has evolved from a common ancestral gene during evolution (45).

The authors would like to thank Dr. Michael Parker for his assistance in the DNA sequence and computer analyses during the early phase of these studies, and Ila McCullough, Margo Rogers, and Lois Swenson for secretarial assistance. This research was supported by a contract between Novo Industries and ZymoGenetics, a research grant from the National Institutes of Health (HL 16919) to E.W.D., and a research grant from Blood Systems, Inc., to W.K.

1. Davie, E. W., Fujikawa, K., Kurachi, K. \& Kisiel, W. (1979) Adv. Enzymol. 48, 277-318.

2. DiScipio, R. G., Hermodson, M. A., Yates, S. G. \& Davie, E. W. (1977) Biochemistry 16, 698-706.

3. McMullen, B. A., Fujikawa, K. \& Kisiel, W. (1983) Biochem. Biophys. Res. Commun. 115, 8-14.

4. Kisiel, W. \& Davie, E. W. (1975) Biochemistry 14, 4928-4934.

5. Radcliffe, R. \& Nemerson, Y. (1975) J. Biol. Chem. 250, 388-395.

6. Broze, G. J. \& Majerus, P. W. (1980) J. Biol. Chem. 255, 1242-1247.

7. Bajaj, S. P., Rapaport, S. I. \& Brown, S. F. (1981) J. Biol. Chem. 256, 253-259.

8. Radcliffe, R. \& Nemerson, Y. (1976) J. Biol. Chem. 251, 4797-4802.

9. Kisiel, W., Fujikawa, K. \& Davie, E. W. (1977) Biochemistry 16, 4189-4194.

10. Radcliffe, R., Bagdasarian, S., Colman, R. \& Nemerson, Y. (1977) Blood 50, 611-617.

11. Seligsohn, U., Osterud, B., Brown, S. F., Griffin, J. H. \& Rapaport, S. I. (1979) J. Clin. Invest. 64, 1056-1065.

12. Osterud, B. \& Rapaport, S. I. (1977) Proc. Natl. Acad. Sci. USA 74, 5260-5264.

13. Jesty, J. \& Silverberg, S. A. (1979) J. Biol. Chem. 254, $12337-12345$.

14. Roberts, H. R. \& Zeitler, K. D. (1982) in Hemostasis and Thrombosis, eds. Colman, R. W., Hirsh, J., Marder, V. J. \& Salzman, E. W. (Lippincott, Philadelphia), pp. 134-137.
15. Hedner, U. \& Kisiel, W. (1983) J. Clin. Invest. 71, 1836-1841.

16. Anson, D. S., Austen, D. E. G. \& Brownlee, G. G. (1985) Nature (London) 315, 683-685.

17. Busby, S., Kumar, A., Joseph, M., Halfpap, L., Insley, M., Berkner, K., Kurachi, K. \& Woodbury, R. (1985) Nature (London) 316, 271-273.

18. De La Salle, H., Altenburger, W., Elkaim, R., Dott, K., Dieterle, A., Drillien, R., Cazenave, J.-P., Tolstoshev, P. \& Lecocq, J.-P. (1985) Nature (London) 316, 268-270.

19. Kwok, S. C. M., Ledley, F. D., Di Lella, A. G., Robson, K. J. H. \& Woo, S. L. C. (1985) Biochemistry 24, 556-561.

20. Gubler, U. \& Hoffman, B. J. (1983) Gene 25, 263-269.

21. Toole, J. J., Knopf, J. L., Wozney, J. M., Sultzman, L. A., Buecker, J. L., Pittman, D. D., Kaufman, R. J., Brown, E., Shoemaker, C., Orr, E. C., Amphlett, G. W., Foster, W. B., Coe, M. L., Knutson, G. J., Fass, D. N. \& Hewick, R. M. (1984) Nature (London) 312, 342-347.

22. Kisiel, W. \& McMullen, B. A. (1981) Thromb. Res. 22, 375-380.

23. Canfield, W. M. \& Kisiel, W. (1982) J. Clin. Invest. 70, 1260-1272.

24. Brown, J. P., Wright, P. W., Hart, G. E., Woodbury, R. G., Hellstrom, K. E. \& Hellstrom, I. (1980) J. Biol. Chem. 255, 4980-4983.

25. Young, R. A. \& Davis, R. W. (1983) Science 222, 778-782.

26. Young, R. A. \& Davis, R. W. (1983) Proc. Natl. Acad. Sci. USA 80, 1194-1198.

27. Benton, W. D. \& Davis, R. W. (1977) Science 196, 180-181.

28. Sanger, F., Nicklen, S. \& Coulson, A. R. (1977) Proc. Natl. Acad. Sci. USA 74, 5463-5467.

29. Maxam, A. M. \& Gilbert, W. (1980) Methods Enzymol. 65, 499-560.

30. Crestfield, A. M., Moore, S. \& Stein, W. H. (1963) J. Biol. Chem. 238, 622-627.

31. Kurachi, K. \& Davie, E. W. (1982) Proc. Natl. Acad. Sci. USA 79, 6461-6464.

32. McMullen, B. A., Fujikawa, K., Kisiel, W., Sasagawa, T., Howald, W. N., Kwa, E. Y. \& Weinstein, B. (1983) Biochemistry 22, 2875-2882.

33. Mott, J. E., Arsdell, J. V. \& Platt, T. (1984) Nucleic Acids Res. 12, 4139-4152.

34. Blobel, G., Walter, P., Chang, C. N., Goldman, B. M., Erickson, A. H. \& Singappa, R. (1979) in Secretory Mechanisms, Society for Experimental Biology Symposium, eds. Hopkins, C. R. \& Duncan, D. J. (Cambridge University Press, London), Vol. 33, pp. 9-36.

35. Degen, S. J. F., MacGillivray, R. T. A. \& Davie, E. W. (1983) Biochemistry 22, 2087-2097.

36. Foster, D. C., Yoshitake, S. \& Davie, E. W. (1985) Proc. Natl. Acad. Sci. USA 82, 4673-4677.

37. Beckmann, R. J., Schmidt, R. J., Santerre, R. F., Plutzky, J., Crabtree, G. R. \& Long, G. L. (1985) Nucleic Acids Res. 13, 5233-5247.

38. Yoshitake, S., Schach, B. G., Foster, D. C., Davie, E. W. \& Kurachi, K. (1985) Biochemistry 24, 3736-3750.

39. Anson, D. S., Choo, K. H., Rees, D. J. G., Giannelli, F., Gould, J. A., Huddleston, J. A. \& Brownlee, G. G. (1984) EMBO J. 3, 1053-1060.

40. Dayhoff, M. O. (1978) Atlas of Protein Sequence and Structure (Natl. Biomed. Res. Found., Washington, DC), Vol. 5, Suppl. 3.

41. Doolittle, R. F., Feng, D. F. \& Johnson, M. S. (1984) Nature (London) 307, 558-560.

42. Drakenberg, T., Fernlund, P., Roepstorff, P. \& Stenflo, J. (1983) Proc. Natl. Acad. Sci. USA 80, 1802-1806.

43. Sigler, P. B., Blow, D. M., Matthews, B. W. \& Henderson, R. (1968) J. Mol. Biol. 35, 143-164.

44. Leytus, S. P., Chung, D. W., Kisiel, W., Kurachi, K. \& Davie, E. W. (1984) Proc. Natl. Acad. Sci. USA 81, 3699-3702.

45. Katayama, K., Ericsson, L. H., Enfield, D. L., Walsh, K. A., Neurath, H., Davie, E. W. \& Titani, K. (1979) Proc. Natl. Acad. Sci. USA 76, 4990-4994. 